\title{
Postmarketing surveillance of safety and effectiveness of etanercept in Japanese patients with rheumatoid arthritis
}

\author{
Takao Koike • Masayoshi Harigai · Shigeko Inokuma • Naoki Ishiguro • \\ Junnosuke Ryu · Tsutomu Takeuchi · Yoshiya Tanaka • Hisashi Yamanaka • \\ Koichi Fujii · Takunari Yoshinaga $\cdot$ Bruce Freundlich $\cdot$ Michio Suzukawa
}

Received: 1 November 2010/Accepted: 2 December 2010/Published online: 25 January 2011

(C) Japan College of Rheumatology 2011

\begin{abstract}
Our aim was to evaluate real-world safety and effectiveness in a 6-month postmarketing surveillance study covering all Japanese patients with rheumatoid arthritis (RA) who received etanercept during a 2-year period. Data for 13,894 patients (1334 sites) enrolled between March 2005 and April 2007 were collected. Adverse events (AEs) and serious adverse events (SAEs) were reported in $4336(31.2 \%)$ and 857 (6.2\%) patients, respectively. The most frequent AEs were injection site reactions $(n=610,4.4 \%)$ and rash $(n=339,2.4 \%)$, whereas pneumonia $(n=116,0.8 \%)$ and interstitial lung disease $(n=77,0.6 \%)$ were the most frequent SAEs. Significant improvement in the proportion of patients with a good European League Against Rheumatism (EULAR) response was observed from week $4(17.6 \%)$ to week 24 $(31.6 \%)(p<0.001) ; 84.3 \%$ of patients had good or moderate EULAR responses at week 24. The percentage of
\end{abstract}

\footnotetext{
T. Koike

Hokkaido University Graduate School of Medicine,

Sapporo, Japan

M. Harigai

Tokyo Medical Dental University Graduate School,

Tokyo, Japan

S. Inokuma

Japanese Red Cross Medical Center, Tokyo, Japan

N. Ishiguro

Nagoya University Graduate School of Medicine, Nagoya, Japan

J. Ryu

Nihon University School of Medicine, Tokyo, Japan

T. Takeuchi

Keio University, Tokyo, Japan
}

patients achieving remission increased significantly from week $4(9.3 \%)$ to week $24(18.9 \%)(p<0.001)$. Patients with early moderate RA were less likely to experience SAEs and were more likely to achieve remission compared with patients with more severe disease. The safety and effectiveness of etanercept was demonstrated in Japanese patients in one of the largest observational trials conducted thus far in RA patients treated with biologics.

Keywords DAS28 - Etanercept · Postmarketing surveillance study $\cdot$ Rheumatoid arthritis

\section{Introduction}

Rheumatoid arthritis (RA), a chronic inflammatory disease affecting joints and extra-articular tissues, is associated

\author{
Y. Tanaka \\ University of Occupational and Environmental Health, \\ Japan, Kitakyushu, Japan \\ H. Yamanaka \\ Tokyo Women's Medical University, Tokyo, Japan \\ K. Fujii - M. Suzukawa \\ Pfizer Japan Inc., Medical Affairs, Tokyo, Japan \\ T. Yoshinaga \\ Pfizer Japan Inc., Postmarketing Surveillance, Tokyo, Japan \\ B. Freundlich $(\bowtie)$ \\ University of Pennsylvania, 1252 Lakemont Road, \\ Villanova, Philadelphia, PA 19085, USA \\ e-mail: BFreundlich@msn.com
}


with increased pain, deterioration of physical function, and decreased life expectancy [1,2]. Achievement of disease remission is considered a realistic and crucial goal for patients with RA, as reflected by current treatment guidelines and recommendations of the European League Against Rheumatism (EULAR), the American College of Rheumatology (ACR), and others [3-5]. The modified disease activity score (DAS28) [6] is a validated 28-joint instrument that measures joint tenderness and/or swelling and can accurately evaluate the status of disease activity and the efficacy of treatment. Because of its reliability in monitoring and defining disease activity and remission, the DAS28 is commonly used in RA trials; it has also been endorsed by the EULAR working group recommendations for management of RA [5, 7].

Recent randomized clinical trials have demonstrated the efficacy and safety profile of RA treatments that function as antagonists of tumor necrosis factor alpha (TNF- $\alpha$ ), either as monotherapy or combined with methotrexate [7-12]. In general, these treatment regimens were effective at reducing disease activity, achieving remission, and preventing joint destruction in patients with RA. However, most of the data describing efficacy and safety for RA treatments come from late-phase clinical trials or national databases. Inclusion criteria for the studies are not always reflective of treatment in a real-world environment. Large welldesigned phase 3 trials generally provide useful patient outcomes data, but these studies may not adequately define the true safety and effectiveness of a drug outside the clinical research setting.

As one of the conditions of approval of etanercept in Japan, the Pharmaceutical and Medical Device Agency (PMDA) requested that Wyeth (now integrated into Pfizer as of October 2009) conduct surveillance to confirm the safety and effectiveness of etanercept in Japanese patients in the clinical setting after the drug was marketed. To comply with this request, we performed a postmarketing surveillance (PMS) study that registered all Japanese RA patients treated with etanercept at the participating study sites for the survey period. Etanercept is a fully human soluble $\mathrm{TNF}-\alpha$ receptor fusion protein with demonstrated efficacy against RA in patients not adequately responding to disease-modifying antirheumatic drugs (DMARDs) such as methotrexate [13, 14]. Etanercept has shown superior efficacy to methotrexate in patients with RA [15], and the combination of etanercept plus methotrexate was superior to either monotherapy alone [16]. The goal of this PMS study was to evaluate the real-world safety and effectiveness of etanercept for a large Japanese patient population receiving etanercept for the treatment of RA. A previous interim analysis comprising data for 7091 of the registered patients reported that etanercept was effective with no new safety signals [17]. This report covers nearly 14,000
Japanese patients with RA registered to the PMS study from 2005 to 2007.

\section{Patients, materials, and methods}

\section{Patients}

Between March 2005 and April 2007, all Japanese patients with RA from 1334 sites were enrolled in a 6-month PMS study of etanercept use (NCT00503503). Patient eligibility for treatment with etanercept was based on the Japan College of Rheumatology treatment guidelines [18]. Briefly, etanercept was indicated for patients with RA who were previously treated with DMARDs (e.g., methotrexate, salazosulfapyridine, or bucillamine) for $>3$ months, and had $\geq 6$ tender joints, $\geq 6$ swollen joints, and erythrocyte sedimentation rate $(\mathrm{ESR}) \geq 28 \mathrm{~mm} / \mathrm{h}$ or C-reactive protein (CRP) levels $\geq 2.0 \mathrm{mg} / \mathrm{dL}$ [17]. Patients had a low risk for opportunistic infections, defined as white blood count $\geq 4000 / \mathrm{mm}^{3}$, peripheral blood lymphocyte count $\geq 1000 /$ $\mathrm{mm}^{3}$, and negative serum $\beta$-D-glucan. Mandatory chest radiographs and tuberculin tests were conducted before initiation of treatment. Information on age, sex, comorbidity, Steinbrocker radiographic stage [19], Steinbrocker functional class [19], duration of RA, smoking history, previous and concomitant use of glucocorticoids, and concomitant use of DMARDs (including methotrexate) was collected. Also, ESR and CRP levels were assessed. Etanercept 10 or $25 \mathrm{mg}$ was administered subcutaneously twice weekly, with the dose determined by the prescribing physician. After an initial 1-month training period, patients were allowed to self-inject etanercept.

The PMS protocol was reviewed and approved by the Japanese Ministry of Health, Labor, and Welfare. Registration was conducted centrally at the time of treatment initiation. Data collection was performed through an electronic data capture system, the Internet, or hardcopy case report forms, and medical representative staff members from Wyeth and Takeda Pharmaceutical Company visited sites periodically to collect additional data as required.

\section{Assessments}

All patients were assessed for safety every 2 weeks. Safety evaluations included all events occurring $\leq 24$ weeks after the first etanercept dose and $\leq 30$ days after the last dose. All adverse events (AEs) were reported. Safety data were coded with preferred terms from the Medical Dictionary for Regulatory Activities [20]. All AEs, serious AEs (SAEs), adverse drug reactions (ADRs; noxious and unintended responses deemed to be related to the treatment), and serious ADRs, including infection, were defined 
based on the International Conference on Harmonisation tripartite harmonised guideline [21]. Particular attention was paid to the occurrence of infections, especially tuberculosis, pneumonia, Pneumocystis jiroveci pneumonia, cytomegalovirus infection, and sepsis and to specific important ADRs that included malignant neoplasm, demyelination, congestive heart failure, injection site reaction, and lupus. Safety information was independently evaluated by the Japan College of Rheumatology PMS committee.

Treatment effectiveness was measured monthly using the EULAR response criteria [22] and the DAS28 [6]. The DAS28 is divided into 4 categories: remission (DAS28 $<2.6$ ), low disease activity (DAS28 $\geq 2.6$ and $\leq 3.2$ ), moderate disease activity (DAS28 $>3.2$ and $\leq 5.1$ ), and high disease activity (DAS28 $>5.1$ ). A good response was defined as a DAS28 improvement from baseline of $>1.2$ and a DAS28 of $\leq 3.2$ during follow-up. Patients with score improvements of $\leq 0.6$ or those with improvements between 0.6 and 1.2 plus a DAS28 of $>5.1$ during followup were defined as nonresponders. Moderate responders were those with DAS28 improvements from baseline between 0.6 and 1.2 plus a DAS28 of $\leq 5.1$ during followup. Treatment was considered to be effective in patients with moderate or good DAS28 responses. General health status was measured using a patients' visual analog scale (100 being the worst they can imagine, 0 being the best they can imagine), and duration of morning stiffness was also assessed.

\section{Statistical analysis}

Missing data were processed using the last-observationcarried-forward method, except for baseline values, which were not carried forward. The $\chi^{2}$ or $t$-test was used to compare differences in baseline values between men and women. The $t$-test was used to compare DAS28 differences between baseline and weeks 4 and $24 ; \chi^{2}$ tests were used to compare differences in EULAR response rates, and Cochran-Armitage tests were used to examine evidence of trends in response rates. Cox proportional hazard models were used to estimate the influence of multiple variables on the occurrence of serious infections (AEs). These variables included the confounders assessed at baseline: age, sex, concomitant methotrexate use, concomitant glucocorticoid use, history of infectious disease, history of tuberculosis, presence of any comorbidities, Steinbrocker functional class, and duration of RA. A total of 1274 patients with missing data [duration of RA $(n=1267)$ and other $(n=7)$ ] were excluded from the Cox proportional hazard models. We also used multiple logistic regression models to estimate the effect of variables on the likelihood of achieving remission. Patients who had missing DAS28 data at either baseline or at 24 weeks, a DAS28 value of $<2.6$ at baseline, or missing data for other adjustment factors were excluded from these models. Furthermore, we used Cox proportional hazard models and multiple logistic regression models to examine the combined effects of multiple risk factors on the occurrence of serious infections and the likelihood of achieving remission, respectively. The hazard ratio or odds ratio and the $95 \%$ confidence interval (CI) for each of the combined factors after adjustment for major confounders and the combined effect relations with numbers of factors were further explored by trend tests. All statistical analyses were performed using SAS $^{\circledR}$ software version 8.2 (SAS Institute, Cary, NC, USA). Two-sided $P$ values of $<0.05$ were considered statistically significant.

\section{Results}

Patients

A total of 13,894 patients treated with etanercept completed the 24-week study (Table 1). The majority of patients were women $(n=11,314 ; 81.4 \%)$. Mean \pm SD patient age was $58.1 \pm 13.1$ years; most patients $(78.3 \%)$ were aged $>50$ years (more than one half were aged $>60$ years), and the mean $\pm \mathrm{SD}$ patient weight was $53.2 \pm 10.1 \mathrm{~kg}$. About $40 \%$ of patients had a disease duration of $>10$ years. Concomitant use of DMARDs/ biologics was $74.0 \%(n=10,276)$ and that of methotrexate was $55.9 \%$ ( $n=7768)$. The most commonly used etanercept dose regimen $(76.1 \% ; n=10,578)$ was $50 \mathrm{mg}$ per week (i.e., $25 \mathrm{mg}$ twice weekly). Previous use of glucocorticoid was $83.4 \%(n=11587)$ and previous use of infliximab was $13.5 \%$ ( $n=1878)$. Additionally, $57.1 \%$ of patients had comorbidities, including 877 patients $(6.3 \%)$ with a medical history of tuberculosis. Significant differences were observed between men and women in most demographic characteristics, including age, weight, disease duration, Steinbrocker stage and class, history of concomitant medical conditions, comorbidities, concomitant use of methotrexate, and prior glucocorticoid use (Table 1). A total of 11,615 (83.6\%) patients completed 24 weeks of therapy, with 2309 patients (16.6\%) discontinuing during the 24-week period. Reasons for stopping treatment were AEs $(7.6 \%, n=1049)$, lack of treatment effectiveness $(2.6 \%, n=368)$, refusal of treatment for economic reasons $(1.5 \%, n=212)$, moved to another hospital $(1.6 \%, n=222)$, and other $(3.3 \%, n=458)$.

\section{Safety}

As shown in Table 2, AEs and SAEs were reported in 4336 $(31.2 \%)$ and $857(6.2 \%)$ patients, respectively. The most 
Table 1 Patient demographics

\begin{tabular}{|c|c|c|c|}
\hline Characteristic & $\begin{array}{l}\text { Male } \\
\text { patients } \\
(n=2580)\end{array}$ & $\begin{array}{l}\text { Female } \\
\text { patients } \\
(n=11,314)\end{array}$ & $p$ value \\
\hline Mean (SD) age, years & $57.5(13.2)$ & $60.7(12.4)$ & $<0.001^{\mathrm{b}}$ \\
\hline \multicolumn{4}{|l|}{ Age range $[n(\%)$, years] } \\
\hline$<20$ & $11(0.4)$ & $65(0.6)$ & \\
\hline $20-29$ & $52(2.0)$ & $342(3.0)$ & \\
\hline $30-39$ & $124(4.8)$ & $843(7.5)$ & \\
\hline $40-49$ & $198(7.7)$ & $1382(12.2)$ & \\
\hline $50-59$ & $691(26.8)$ & $3243(28.7)$ & \\
\hline $60-69$ & $837(32.4)$ & 3358 (29.7) & \\
\hline$\geq 70$ & $667(25.9)$ & $2081(18.4)$ & $<0.001$ \\
\hline Mean (SD) weight, kg & $61.7(10.4)$ & $51.3(9.0)$ & $<0.001^{\mathrm{b}}$ \\
\hline \multicolumn{4}{|l|}{ Disease duration $[n(\%)$, years] } \\
\hline$<2$ & $436(16.9)$ & $1168(10.3)$ & \\
\hline $2-<5$ & $588(22.8)$ & $1844(16.3)$ & \\
\hline $5-<10$ & $589(22.8)$ & $2386(21.1)$ & \\
\hline $10-<15$ & $328(12.7)$ & $1925(17.0)$ & \\
\hline $15-<20$ & $194(7.5)$ & $1166(10.3)$ & \\
\hline$\geq 20$ & $208(8.1)$ & 1795 (15.9) & \\
\hline Unknown (years) & $237(9.2)$ & $1030(9.1)$ & $<0.001$ \\
\hline \multicolumn{4}{|l|}{ Steinbrocker stage $[n(\%)]$} \\
\hline I & $241(9.4)$ & $624(5.5)$ & \\
\hline II & $801(31.1)$ & $2458(21.7)$ & \\
\hline III & $928(36.0)$ & $3998(35.4)$ & \\
\hline IV & $606(23.5)$ & $4225(37.4)$ & $<0.001$ \\
\hline \multicolumn{4}{|l|}{ Steinbrocker class $[n(\%)]$} \\
\hline 1 & $277(10.8)$ & $946(8.4)$ & \\
\hline 2 & $1536(59.6)$ & $6526(57.7)$ & \\
\hline 3 & $694(26.9)$ & $3482(30.8)$ & \\
\hline 4 & $69(2.7)$ & $351(3.1)$ & $<0.001$ \\
\hline $\begin{array}{l}\text { Positive history of concomitant } \\
\text { medical conditions }[n(\%)]\end{array}$ & $987(38.8)$ & 3079 (27.6) & $<0.001$ \\
\hline Tuberculosis & $228(8.8)$ & $649(5.7)$ & $<0.001$ \\
\hline Interstitial pneumonitis & $341(13.2)$ & $693(6.1)$ & $<0.001$ \\
\hline Follicular bronchitis & $5(0.2)$ & $32(0.3)$ & \\
\hline COPD & $43(1.7)$ & $41(0.4)$ & $<0.001$ \\
\hline Total comorbidities $[n(\%)]$ & $1570(60.9)$ & $6359(56.2)$ & $<0.001$ \\
\hline Hepatic & $155(6.0)$ & $475(4.2)$ & $<0.001$ \\
\hline Renal & $152(5.9)$ & $395(3.5)$ & $<0.001$ \\
\hline Hematologic & $100(3.9)$ & $698(6.2)$ & $<0.001$ \\
\hline Cardiac & $217(8.4)$ & $569(5.0)$ & $<0.001$ \\
\hline Infectious (nonserious) & $56(2.2)$ & $168(1.5)$ & 0.013 \\
\hline Diabetes mellitus & $340(13.2)$ & $758(6.7)$ & $<0.001$ \\
\hline
\end{tabular}

Weekly etanercept dose regimen $[n(\%), \mathrm{mg}]$

\begin{tabular}{lccc}
50 & $2018(78.2)$ & $8560(75.7)$ & \\
25 & $264(10.2)$ & $1298(11.5)$ & \\
20 & $2(0.1)$ & $27(0.2)$ & \\
$20-50^{\mathrm{c}}$ & $296(11.5)$ & $1429(12.6)$ & $0.023^{\mathrm{d}}$ \\
\hline
\end{tabular}

Table 1 continued

\begin{tabular}{|c|c|c|c|}
\hline Characteristic & $\begin{array}{l}\text { Male } \\
\text { patients } \\
(n=2580)\end{array}$ & $\begin{array}{l}\text { Female } \\
\text { patients } \\
(n=11,314)\end{array}$ & $p$ value $^{\mathrm{a}}$ \\
\hline $\begin{array}{l}\text { Concomitant DMARD/ } \\
\text { biologic use }[n(\%)]\end{array}$ & $1924(74.6)$ & $8352(73.8)$ & \\
\hline $\begin{array}{l}\text { Prior glucocorticoid use } \\
{[n(\%)]^{\mathrm{e}}}\end{array}$ & $2209(88.4)$ & $9378(85.5)$ & $<0.001$ \\
\hline Concomitant MTX use $[n(\%)]$ & $1371(53.1)$ & $6397(56.5)$ & 0.002 \\
\hline \multicolumn{4}{|l|}{ MTX dose $[n(\%), \mathrm{mg} /$ week $]$} \\
\hline $0-<4$ & $39(2.8)$ & $271(4.2)$ & \\
\hline $4-<6$ & $239(17.4)$ & $1583(24.7)$ & \\
\hline $6-<8$ & $448(32.7)$ & $2157(33.7)$ & \\
\hline $8-<10$ & $497(36.3)$ & $1898(29.7)$ & \\
\hline$\geq 10$ & $148(10.8)$ & $488(7.6)$ & $<0.001$ \\
\hline Prior infliximab use $[n(\%)]$ & $366(14.2)$ & $1512(13.4)$ & \\
\hline
\end{tabular}

COPD chronic obstructive pulmonary disease, DMARD diseasemodifying antirheumatic drug, $M T X$ methotrexate

a The $p$ values indicated are for comparisons between male and female patient data, using $\chi^{2}$ tests unless otherwise indicated

${ }^{\mathrm{b}}$ Comparisons were made using the $t$-test

${ }^{c}$ Patients received variable dosing during the observation period

${ }^{d}$ Comparisons were made using Fisher exact test

e Unknown patients were omitted from the percentage calculation

frequently observed AEs were injection site reaction $(n=610,4.4 \%)$, rash $(n=339,2.4 \%)$, and abnormal hepatic function $(n=328,2.4 \%)$. Pneumonia was the most frequently reported $\operatorname{SAE}(n=116,0.8 \%)$, followed by interstitial lung disease $(n=77,0.6 \%)$, and pyrexia $(n=40,0.3 \%)$. In total, 26.7 and $4.6 \%$ of patients reported ADRs and serious ADRs, respectively. Table 2 also lists selected important ADRs; various forms of pneumonia were the most common ADR $(n=174,1.3 \%)$. Tuberculosis was reported as an ADR in 12 patients $(0.1 \%)$, and interstitial lung disease in 81 patients $(0.6 \%)$. No cases of demyelinating disease were observed. Lupus-like syndrome and congestive heart failure (including all heart failure) were recorded as ADRs in 5 and 7 patients, respectively. Thirty cases of malignancy were reported $(0.2 \%)$, and there were 76 deaths $(0.6 \%)$ during the 24-week study.

Risk factors for the development of serious infections are shown in Table 3. Compared with the respective referent group, female sex and concomitant methotrexate use significantly lowered the risk of infection, whereas older age ( $\geq 65$ years), history of infectious disease, presence of any comorbidities, Steinbrocker functional class 4 , and concomitant glucocorticoid use significantly increased serious infection risk. Prior history of tuberculosis slightly, but not significantly, raised the infection risk compared 
Table 2 Incidences of the most commonly reported adverse events, serious adverse events, important adverse drug reactions, and death

\begin{tabular}{|c|c|}
\hline Event & $n(\%)$ \\
\hline Patients with at least $1 \mathrm{AE},{ }^{\mathrm{a}}$ total & $4336(31.2)$ \\
\hline Injection site reaction & $610(4.4)$ \\
\hline Rash & $339(2.4)$ \\
\hline Abnormal hepatic function & $328(2.4)$ \\
\hline Nasopharyngitis & $288(2.1)$ \\
\hline Pyrexia & $261(1.9)$ \\
\hline Upper respiratory tract infection & $224(1.6)$ \\
\hline Pruritus & $202(1.5)$ \\
\hline Total pneumonia ${ }^{\mathrm{b}}$ & $189(1.0)$ \\
\hline Herpes zoster & $115(0.8)$ \\
\hline Erythema & $114(0.8)$ \\
\hline Patients with at least $1 \mathrm{SAE},{ }^{\mathrm{a}}$ total & $857(6.2)$ \\
\hline Total pneumonia ${ }^{\mathrm{b}}$ & $116(0.8)$ \\
\hline Interstitial lung disease & $77(0.6)$ \\
\hline Pyrexia & $40(0.3)$ \\
\hline Sepsis & $27(0.2)$ \\
\hline Herpes zoster & $23(0.2)$ \\
\hline Pneumocystis jiroveci pneumonia & $24(0.2)$ \\
\hline Urinary tract infection & $16(0.1)$ \\
\hline Abnormal hepatic function & $15(0.1)$ \\
\hline Bacterial arthritis & $13(0.1)$ \\
\hline Bronchitis & $13(0.1)$ \\
\hline Patients with at least 1 important $\mathrm{ADR}^{\mathrm{a}}$ & $968(7.0)^{\mathrm{c}}$ \\
\hline Total pneumonia $^{\mathrm{b}}$ & $174(1.3)$ \\
\hline Interstitial lung disease & $81(0.6)$ \\
\hline Pneumocystis jiroveci pneumonia & $25(0.2)$ \\
\hline Malignancy & $30(0.2)$ \\
\hline Tuberculosis $^{\mathrm{d}}$ & $12(0.1)$ \\
\hline Pulmonary & $10(0.1)$ \\
\hline Extrapulmonary & $3(<0.1)$ \\
\hline Congestive heart failure & $7(0.1)$ \\
\hline Lupus-like syndrome & $5(<0.1)$ \\
\hline Demyelinating disease & $0(0)$ \\
\hline Deaths & $76(0.6)$ \\
\hline
\end{tabular}

$A D R$ adverse drug reaction, $A E$ adverse event, $S A E$ serious adverse event

${ }^{\text {a }}$ Patients who had at least $1 \mathrm{AE}, \mathrm{SAE}$, or specifically important ADR, respectively. The 10 most frequently reported AEs, SAEs, and ADRs are listed

b Total pneumonia $=$ pneumonia + bacterial pneumonia + bronchopneumonia + Chlamydia pneumonia + staphylococcal pneumonia + Candida pneumonia + fungal pneumonia; 1 patient developed both pneumonia and bronchopneumonia

c 609 patients who had injection site reactions were included

d 1 patient had both pulmonary and extrapulmonary tuberculosis

with those without a history of tuberculosis (model 1). Model 2 showed the combined effects of multiple risk factors on the occurrence of serious infections adjusted for the remaining variables included in model 1. Compared with patients without combined risk factors, the hazard ratio of serious infection was 9.91 (95\% CI 5.48-17.94; $p<0.001)$ for patients who had 3 risk factors, 4.24 (95\% CI $2.83-6.34 ; p<0.001)$ for patients who had 2 risk factors, and 1.96 (95\% CI 1.30-2.96; $p=0.001$ ) for patients who had 1 risk factor. Highly significant linear association $(p<0.001)$ was evident for increasing number of combined risk factors.

\section{Effectiveness}

The effectiveness of etanercept treatment as determined by various assessment methods is shown in Table 4. The mean DAS28 decreased significantly (both $p<0.01$ ), from 5.9 at baseline to 4.3 at week 4 (27\% improvement) and 3.8 at week 24 (36\% improvement). The mean duration of morning stiffness also decreased significantly (both $p<0.01$ ), from $111.3 \mathrm{~min}$ at baseline to $44.2 \mathrm{~min}$ at week $4(60 \%$ improvement) and $31.1 \mathrm{~min}$ at week 24 (72\% improvement). The mean numbers of tender joints (9.2 at baseline, 4.2 at week 4, and 3.0 at week 24 ) and swollen joints (8.6, 4.1, and 2.8 , respectively), and the mean general health status (60.1, 36.6, and $30.7 \mathrm{~mm}$, respectively, by patients' visual analog scale) all showed significant (all $p<0.01$ ) improvements from baseline at weeks 4 and 24 . The mean ESR improved significantly, from $58.7 \mathrm{~mm} / \mathrm{h}$ (baseline) to $38.1 \mathrm{~mm} / \mathrm{h}$ (week 4) and $34.8 \mathrm{~mm} / \mathrm{h}$ (week 24), representing improvements of 35 and $41 \%$, respectively (both $p<0.01$ ). The mean levels of CRP decreased significantly (both $p<0.01$ ), from $3.6 \mathrm{mg} / \mathrm{dL}$ at baseline to $1.4 \mathrm{mg} / \mathrm{dL}$ at week $4(61 \%$ improvement) and $1.2 \mathrm{mg} / \mathrm{dL}$ at week $24 \quad(67 \%$ improvement).

The EULAR response and DAS28 remission rate were also evaluated. At week 4, 779 patients (17.6\%) had achieved a good EULAR response; a trend of significant improvement occurred throughout the observation period, with 2336 patients (31.6\%) having a good response by week 24 ( $p<0.001$ for trend; Fig. 1a). At week $4,77.0 \%$ of patients had achieved a good or moderate response; response rates increased from week 4 to 24 , with $84.3 \%$ of patients achieving a good or moderate response by week 24 . A total of $1161(15.7 \%)$ patients had no response to etanercept at week 24 (Fig. 1a). Remission was reported in 1395 patients $(18.9 \%)$ at week 24 , with significant improvement noted during the observation period ( $p<0.001$ for trend; Fig. 1b). Low, moderate, and high disease activity were reported in 1179 (15.9\%), 3730 (50.4\%), and 1091 (14.8\%) patients, respectively, at week 24 (Fig. 1b).

Factors that affected the odds of achieving RA remission are shown in Table 5. Compared with the referent group in model 1 , male sex, younger age ( $<65$ years), concomitant methotrexate use, lower baseline DAS28 (moderate 
Table 3 Hazard ratios for serious infection (adverse events)

\begin{tabular}{|c|c|c|c|}
\hline Variable & HR & $95 \% \mathrm{CI}$ & $p$ value \\
\hline \multicolumn{4}{|l|}{ Model $1^{\mathrm{a}}$} \\
\hline Sex (women vs. men) & 0.63 & $0.50-0.81$ & $<0.001$ \\
\hline Age $(\geq 65$ vs. $<65$ years of age $)$ & 1.66 & $1.33-2.07$ & $<0.001$ \\
\hline History of infectious disease (yes vs. no) & 2.26 & $1.38-3.70$ & 0.001 \\
\hline History of tuberculosis (yes vs. no) & 1.24 & $0.85-1.80$ & 0.274 \\
\hline Presence of any comorbidities (yes vs. no) & 2.72 & $2.02-3.66$ & $<0.001$ \\
\hline Steinbrocker functional class ( 4 vs. $1+2+3$ ) & 2.54 & $1.73-3.71$ & $<0.001$ \\
\hline \multicolumn{4}{|l|}{ Duration of RA (years) } \\
\hline$\geq 5$ and $<10$ vs. $<5$ & 1.20 & $0.89-1.61$ & 0.237 \\
\hline$\geq 10$ and $<15$ vs. $<5$ & 1.01 & $0.72-1.41$ & 0.971 \\
\hline$\geq 15$ vs. $<5$ & 1.04 & $0.78-1.40$ & 0.774 \\
\hline Concomitant use of MTX (yes vs. no) & 0.59 & $0.47-0.74$ & $<0.001$ \\
\hline Concomitant use of glucocorticoids (yes vs. no) & 2.03 & $1.46-2.84$ & $<0.001$ \\
\hline \multicolumn{4}{|l|}{ Model $2^{\mathrm{b}}$} \\
\hline \multicolumn{4}{|l|}{ Presence of combined risk factors ${ }^{\mathrm{c}}$} \\
\hline 1 vs. 0 & 1.96 & $1.30-2.96$ & 0.001 \\
\hline 2 vs. 0 & 4.24 & $2.83-6.34$ & $<0.001$ \\
\hline 3 vs. 0 & 9.91 & $5.48-17.94$ & $<0.001$ \\
\hline
\end{tabular}

$H R$ hazard ratio, $C I$ confidence interval, $M T X$ methotrexate

${ }^{\text {a }}$ Cox proportional hazard model (for all cases, $n=12,620$ and for serious infection cases, $n=330$ )

b Results were adjusted for sex, age, history of infectious disease, history of tuberculosis, duration of rheumatoid arthritis (RA), and concomitant use of glucocorticoid

${ }^{\mathrm{c}}$ Combined factors: Steinbrocker functional class $=4$, concomitant use of MTX $=$ no, any comorbidities $=$ yes; $p<0.001$ for linear trend using the Wald test

Table 4 Measures of effectiveness

\begin{tabular}{|c|c|c|c|c|c|c|}
\hline Measure & $\begin{array}{l}\text { Baseline, } \\
\text { mean (SD) }\end{array}$ & $\begin{array}{l}\text { Patients evaluated } \\
\text { at baseline }(n)\end{array}$ & $\begin{array}{l}\text { Week } 4 \text {, } \\
\text { mean }(\mathrm{SD})^{\mathrm{a}}\end{array}$ & $\begin{array}{l}\text { Patients evaluated } \\
\text { at week } 4(n)\end{array}$ & $\begin{array}{l}\text { Week } 24 \text {, } \\
\text { mean }(\mathrm{SD})^{\mathrm{a}}\end{array}$ & $\begin{array}{l}\text { Patients evaluated } \\
\text { at week } 24(n)\end{array}$ \\
\hline DAS28 & $5.9(1.2)$ & 8902 & $4.3(1.3)$ & 4754 & $3.8(1.3)$ & 8137 \\
\hline Duration of morning stiffness (min) & $111.3(181.3)$ & 5858 & $44.2(114.0)$ & 3201 & $31.1(90.1)$ & 5058 \\
\hline Tender joints $(n)$ & $9.2(7.0)$ & 12727 & $4.2(4.8)$ & 7873 & $3.0(4.1)$ & 12321 \\
\hline Swollen joints $(n)$ & $8.6(6.2)$ & 12727 & $4.1(4.3)$ & 7871 & $2.8(3.6)$ & 12319 \\
\hline $\begin{array}{l}\text { General health status } \\
\text { (patient visual analog scale) (mm) }\end{array}$ & $60.1(22.7)$ & 11535 & $36.6(22.5)$ & 6702 & $30.7(22.1)$ & 10616 \\
\hline $\operatorname{ESR}(\mathrm{mm} / \mathrm{h})$ & $58.7(33.0)$ & 9719 & $38.1(27.7)$ & 5732 & $34.8(27.5)$ & 9484 \\
\hline CRP (mg/dL) & $3.6(3.3)$ & 12693 & $1.4(2.1)$ & 8298 & $1.2(2.0)$ & 12770 \\
\hline
\end{tabular}

CRP C-reactive protein, DAS28 modified disease activity score including a 28-joint count, ESR erythrocyte sedimentation rate

a All comparisons differed significantly ( $p<0.01$ vs. baseline), by $t$-test

disease), and better Steinbrocker functional class (1-3) significantly improved the odds of achieving remission. Shorter duration of RA also significantly improved the chances of achieving remission compared with those with $\geq 15$ years' duration (odds ratio [OR] 1.62; 95\% CI 1.36-1.92). Model 2 showed the combined effects of multiple risk factors on the likelihood of achieving remission. Compared with the groups with zero risk factors, the odds ratio of achieving remission was 6.30 (95\% CI 4.83-8.21; $p<0.001)$ for patients who had 4 risk factors, 3.20 (95\% CI 2.64-3.88; $P<0.001$ ) for patients who had 3 risk factors, and 1.87 (95\% CI 1.55-2.26; $p<0.001)$ for patients who had 2 risk factors. Highly significant linear association ( $p<0.001$ ) was evident for increasing number of combined risk factors. When we added 79 patients with lower disease activity (baseline DAS28, $\geq 2.6$ and $\leq 3.2$ ) 


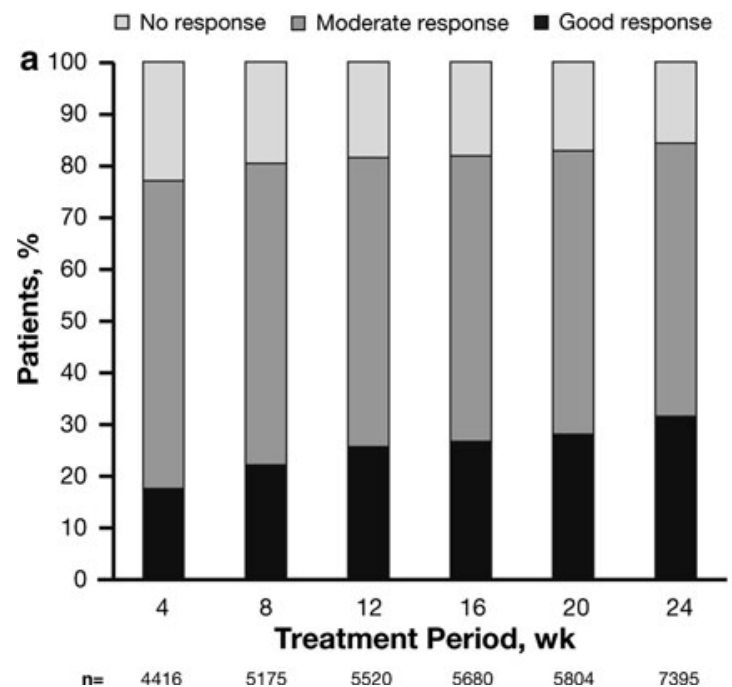

Fig. 1 Time course of a EULAR response and b DAS28 from week 4 to week 24. DAS28 modified disease activity score including a 28-joint count, EULAR European League Against Rheumatism.

Table 5 Odds ratios for achieving remission

\begin{tabular}{lrrr}
\hline Variable & OR & $95 \%$ CI & $p$ value \\
\hline Model 1 & & & \\
Sex (men vs. women) & 1.30 & $1.10-1.53$ & 0.002 \\
Age (<65 vs. $\geq 65$ years of age) & 1.43 & $1.23-1.65$ & $<0.001$ \\
Steinbrocker functional class (1-3 vs. 4) & 2.41 & $1.30-4.49$ & 0.006 \\
Duration of RA (years) & & & \\
$\quad<5$ vs. $\geq 15$ & 1.62 & $1.36-1.92$ & $<0.001$ \\
$5-10$ vs. $\geq 15$ & 1.17 & $0.97-1.42$ & 0.098 \\
$10-15$ vs. $\geq 15$ & 1.04 & $0.84-1.28$ & 0.733 \\
DAS28 at baseline (moderate vs. high) & 2.95 & $2.59-3.37$ & $<0.001$ \\
Concomitant use of MTX & & & \\
$\quad<8$ mg/week vs. none & 1.30 & $1.13-1.49$ & $<0.001$ \\
$\quad \geq 8$ mg/week vs. none & 1.74 & $1.32-2.28$ & $<0.001$ \\
Previous treatment with infliximab & 0.65 & $0.53-0.81$ & $<0.001$ \\
(yes vs. no) & & & \\
Model 2 & & & \\
Presence of combined risk factors ${ }^{\mathrm{b}}$ & & & \\
4 vs. 0-1 & 6.30 & $4.83-8.21$ & $<0.001$ \\
3 vs. 0-1 & 3.20 & $2.64-3.88$ & $<0.001$ \\
2 vs. 0-1 & 1.87 & $1.55-2.26$ & $<0.001$ \\
\hline
\end{tabular}

Multiple logistic regression models [for all cases, $n=6763$ (79 patients with low disease activity were excluded) and for remission cases, $n=1234$ ]

DAS28 modified disease activity score including a 28 -joint count, $M T X$ methotrexate, $O R$ odds ratio, $R A$ rheumatoid arthritis

${ }^{a}$ Results were adjusted for sex, age, and previous treatment with infliximab

b Combined factors: Steinbrocker functional class $=1-3$; MTX $=$ yes; baseline DAS28 $=>3.2$ and $\leq 5.1$ (moderate disease); duration of $\mathrm{RA}<5$ years; $p<0.001$ for linear trend using the Wald test

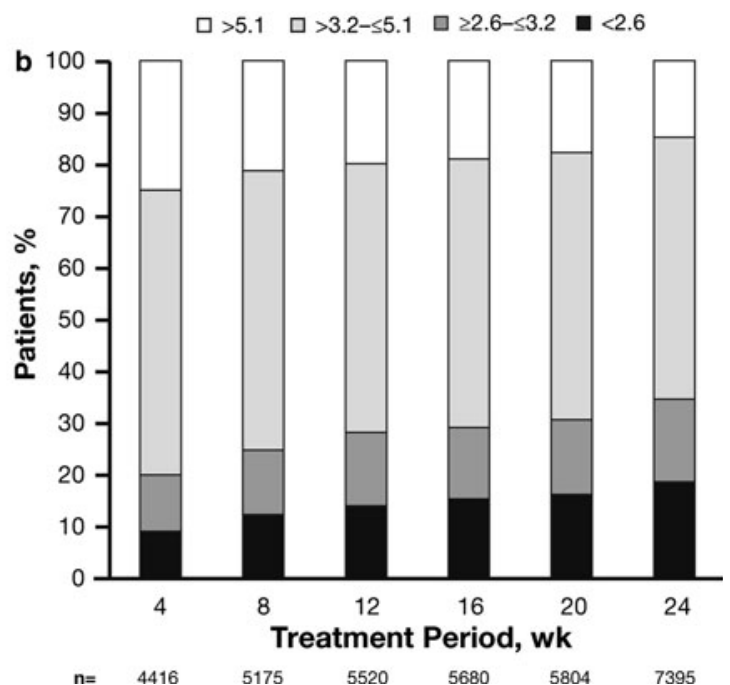

Cochran-Armitage tests were used to examine evidence of trends in response rates; trends for good response rate and remission rate were statistically significant $(p<0.001)$. wk Week

into the lower baseline DAS28 group to examine the odds ratio of achieving remission, a similar pattern was seen (data not shown).

\section{Discussion}

The current trial was one of the largest surveillance studies of biologic use in the rheumatology area, with nearly 14,000 patients registered. Mandatory registration for all patients treated with etanercept occurred at participating sites in Japan during the 2-year study period. This PMS study provided a unique opportunity to capture real-world safety and effectiveness data for a large patient population in an Asian country. Although there are published accounts of other PMS studies with RA biologic treatments [23-25], the large number of patients registered in the current study allowed for the safety and effectiveness of etanercept to be documented in a real-world clinical setting in Japan. The advantage of conducting a study like this is a high precision of AE incidence, remission rate, and other important data.

In the current PMS study, AEs and SAEs were reported in 31.2 and $6.2 \%$ of patients, respectively. A good or moderate response (i.e., effective treatment) occurred in a very high percentage of patients from week 4 to 24 . These data are consistent with those reported in the interim analysis from this study [17]. No new signaling risk factors for serious infection were observed in this PMS study.

Real-world efficacy data were also reported from the Rheumatoid Arthritis DMARD Intervention and Utilization Study (RADIUS), a 5-year, multicenter, observational 
registry of patients treated with etanercept and other RA therapies in the United States ( $N=10,061$ in 2 cohorts) $[26,27]$. Although safety data have not yet been reported, patients treated with etanercept, with $(p<0.01)$ or without $(p<0.05)$ methotrexate, were significantly more likely to have a modified ACR $20 \%$ response at 12 months compared with those receiving only methotrexate. In another PMS study involving TNF- $\alpha$ antagonists, Feltelius et al. [23] collected safety and effectiveness data from 1999 to 2003 in the cohort of all etanercept-treated Swedish patients with RA $(N=1073)$. The 24-month incidence rates of ADRs and SAEs of 27 and 7\%, respectively, in that study are both similar to those observed in the current PMS study. A good or moderate EULAR response rate was observed in $86 \%$ of 517 patients, which is similar to the rate reported in our analysis $(84.3 \%)$ at week 24 .

Because the registered patients in the current PMS study had varied backgrounds, multivariate analyses were conducted to ascertain risk factors related to safety and effectiveness in a real-world setting. The current PMS study identified several factors that improved the safety and effectiveness outcomes of patients treated with etanercept. Patients were more likely to achieve DAS28 remission if they had moderate disease activity, better Steinbrocker functional class, shorter disease duration, and received concomitant methotrexate treatment. Importantly, patients who had a combination of these factors showed a higher probability of achieving remission.

Cox proportional hazard model results also demonstrated several risk factors for serious infection. A combination of Steinbrocker functional class 4, no use of concomitant methotrexate, and the presence of any comorbidities significantly increased the risk for developing serious infection. Thus, the combined use of etanercept and methotrexate in patients with early moderate RA with less comorbidity and better physical function appears to provide patient benefit for the achievement of remission and lowering of SAE occurrences.

Interpretation of these data is somewhat limited by the fact that no control arm was included in this large PMS study. This makes it difficult to distinguish outcomes relating to etanercept treatment from those caused by other factors (e.g., patient expectations, natural history of the disease, or concomitant treatments). The study length (6 months) allowed for the collection of important safety and effectiveness data, but longer-term studies would also be useful. Additionally, evaluations of effectiveness did not include radiographic analysis to confirm the effectiveness of treatment.

This PMS study collected safety and effectiveness data for every Japanese patient with RA receiving etanercept at the participating study sites for a 2-year period. With nearly 14,000 patients registered, this represents one of the largest observational surveillance studies conducted to date in RA patients treated with biologics. The safety and effectiveness data reported here support data from previous clinical trials with etanercept and are also consistent with the data from the interim analysis of this study. Additional subgroup analyses from this study may enable the identification of important factors affecting the safety and effectiveness of etanercept so that treatment decisions can be further optimized.

Acknowledgments The authors wish to acknowledge the contributions of the late Professor Kazuhiko Inoue, MD, PhD, who participated in this work. This report was prepared with the assistance of Joanne Foehl (previously of Pfizer Inc., Global Medical Affairs) and Complete Healthcare Communications Inc., Chadds Ford, PA, USA. This study was sponsored by Wyeth, and clinical fees were shared by Wyeth K.K. and Takeda Pharmaceutical Company Limited, Wyeth K.K.'s copromotion partner for etanercept in Japan. Wyeth was integrated into Pfizer in October 2009. Pursuant to the Pharmaceutical Affairs Law of Japan and the regulations promulgated thereunder, the Sponsor (Wyeth) was required to conduct a PMS program as a condition for the marketing approval of etanercept. Wyeth was responsible for the development of the study protocol (with instruction from the PMDA and advice from the Japan College of Rheumatology (JCR) PMS committee) and for the initial analysis of the data.

Conflict of interest Doctors T. Koike, M. Harigai, S. Inokuma, N. Ishiguro, J. Ryu, T. Takeuchi, Y. Tanaka, and H. Yamanaka are all members of the Etanercept Postmarketing Surveillance Committee of the Japan College of Rheumatology. It is the belief of the first author that this position does not constitute a Conflict of Interest. The doctors participated in the review and analysis of the PMS data in their capacity as Committee members and are so listed. The financial relationships of the authors with all manufacturers of biological products used in the management of RA are as follows. \#1 is a research grant to the institute to which they are affiliated, \#2 is a consulting fee, \#3 is membership of a speakers' bureau, \#4 is a fulltime employee, and \#5 is a previous employee of Pfizer. T. Koike, Abbott Japan, 1; Bristol-Myers Squibb, 1; Chugai Pharmaceutical Co. Ltd, 1; Eisai Co. Ltd, 1; Mitsubishi Tanabe Pharma, 1; Takeda Pharmaceutical Co. Ltd, 1; Wyeth KK, 1; Otsuka Pharmaceutical Co. Ltd, 2; Abbott Japan, 3; Bristol-Myers Squibb, 3; Chugai Pharmaceutical Co. Ltd, 3; Eisai Co. Ltd, 3; Mitsubishi Tanabe Pharma, 3; Takeda Pharmaceutical Co. Ltd, 3; Wyeth KK, 3; M. Harigai, Abbott Japan, 1; Bristol-Myers Squibb, 1; Chugai Pharmaceutical Co. Ltd, 1; Eisai Co. Ltd, 1; Mitsubishi Tanabe Pharma, 1; Pfizer Japan Inc., 1; Takeda Pharmaceutical Co. Ltd, 1; Abbott Japan, 2; Chugai Pharmaceutical Co. Ltd, 2; Mitsubishi Tanabe Pharma, 2; Abbott Japan, 3; Bristol-Myers Squibb, 3; Chugai Pharmaceutical Co. Ltd, 3; Eisai Co. Ltd, 3; Mitsubishi Tanabe Pharma, 3; Pfizer Japan Inc., 3; Takeda Pharmaceutical Co. Ltd, 3; S. Inokuma, None; N. Ishiguro, Abbott, 1; Chugai Pharmaceutical Co. Ltd, 1; Daiichi-Sankyo Pharmaceutical Co. Ltd, 1; Eisai Co. Ltd, 1; Mitsubishi Tanabe Pharma, 1; Takeda Pharmaceutical Co. Ltd, 1; Wyeth KK, 1; Abbott, 3; Bristol-Myers Squibb, 3; Chugai Pharmaceutical Co. Ltd, 3; Daiichi-Sankyo Pharmaceutical Co. Ltd, 3; Eisai Co. Ltd, 3; Mitsubishi Tanabe Pharma, 3; Takeda Pharmaceutical Co. Ltd, 3; Wyeth KK, 3; J. Ryu, None; T. Takeuchi, Bristol-Myers Squibb, 2; Mitsubishi Tanabe Pharma, 2; Novartis, 2; Abbott, 3; Chugai Pharmaceutical Co. Ltd, 3; Eisai Pharma, 3; Mitsubishi Tanabe Pharma, 3; Takeda Pharmaceutical Co. Ltd, 3; Y. Tanaka, Abbott, 1; Astellas Pharma Inc., 1; Chugai Pharmaceutical Co. Ltd, 1; Eisai Co. Ltd, 1; Mitsubishi Tanabe Pharma, 1; MSD KK, 1; Pfizer Inc., 1; Takeda Pharmaceutical Co. Ltd, 1; Mitsubishi Tanabe Pharma, 2; Abbott, 3; Astellas Pharma Inc., 3; Chugai Pharmaceutical Co. Ltd, 3; Eisai Co. Ltd, 3; Mitsubishi 
Tanabe Pharma, 3; Takeda Pharmaceutical Co. Ltd, 3; H. Yamanaka, Abbott Japan, 1; Chugai Pharmaceutical Co. Ltd, 1; Eisai Co. Ltd, 1; Mitsubishi Tanabe Pharma, 1; Takeda Pharmaceutical Co. Ltd, 1; Wyeth KK, 1; Abbott Japan, 3; Chugai Pharmaceutical Co. Ltd, 3; Eisai Co. Ltd, 3; Mitsubishi Tanabe Pharma, 3; Pfizer Japan Inc., 3; Takeda Pharmaceutical Co. Ltd, 3; Wyeth KK, 3; B. Freundlich, Pfizer Inc., 5; K. Fujii, Pfizer Japan Inc., 4; T. Yoshinaga, Pfizer Japan Inc., 4; M. Suzukawa, Pfizer Japan Inc., 4.

\section{References}

1. Drossaers-Bakker KW, de Buck M, van Zeben D, Zwinderman AH, Breedveld FC, Hazes JM. Long-term course and outcome of functional capacity in rheumatoid arthritis: the effect of disease activity and radiologic damage over time. Arthritis Rheum. 1999;42(9):1854-60.

2. Pincus T, Sokka T, Wolfe F. Premature mortality in patients with rheumatoid arthritis: evolving concepts. Arthritis Rheum. 2001;44(6):1234-6.

3. American College of Rheumatology Subcommittee on Rheumatoid Arthritis Guidelines. Guidelines for the management of rheumatoid arthritis: 2002 update. Arthritis Rheum. 2002;46(2): 328-46.

4. Smolen JS, Aletaha D. What should be our treatment goal in rheumatoid arthritis today? Clin Exp Rheumatol. 2006;24(6 suppl 43): S-7-13.

5. Combe B, Landewe R, Lukas C, Bolosiu HD, Breedveld F, Dougados M, et al. EULAR recommendations for the management of early arthritis: report of a task force of the European Standing Committee for International Clinical Studies Including Therapeutics (ESCISIT). Ann Rheum Dis. 2007;66(1):34-45.

6. Prevoo ML, van 't Hof MA, Kuper HH, van Leeuwen MA, van de Putte LB, van Riel PL. Modified disease activity scores that include twenty-eight-joint counts. Development and validation in a prospective longitudinal study of patients with rheumatoid arthritis. Arthritis Rheum. 1995;38(1):44-8.

7. Emery P, Breedveld FC, Hall S, Durez P, Chang DJ, Robertson $\mathrm{D}$, et al. Comparison of methotrexate monotherapy with a combination of methotrexate and etanercept in active, early, moderate to severe rheumatoid arthritis (COMET): a randomised, doubleblind, parallel treatment trial. Lancet. 2008;372(9636):375-82.

8. Breedveld FC, Weisman MH, Kavanaugh AF, Cohen SB, Pavelka K, van Vollenhoven R, et al. The PREMIER study: a multicenter, randomized, double-blind clinical trial of combination therapy with adalimumab plus methotrexate versus methotrexate alone or adalimumab alone in patients with early, aggressive rheumatoid arthritis who had not had previous methotrexate treatment. Arthritis Rheum. 2006;54(1):26-37.

9. van de Putte LB, Atkins C, Malaise M, Sany J, Russell AS, van Riel PL, et al. Efficacy and safety of adalimumab as monotherapy in patients with rheumatoid arthritis for whom previous disease modifying antirheumatic drug treatment has failed. Ann Rheum Dis. 2004;63(5):508-16.

10. van Riel PL, Taggart AJ, Sany J, Gaubitz M, Nab HW, Pedersen $R$, et al. Efficacy and safety of combination etanercept and methotrexate versus etanercept alone in patients with rheumatoid arthritis with an inadequate response to methotrexate: the ADORE study. Ann Rheum Dis. 2006;65(11):1478-83.

11. Goekoop-Ruiterman YP, de Vries-Bouwstra JK, Allaart CF, van Zeben D, Kerstens PJ, Hazes JM, et al. Comparison of treatment strategies in early rheumatoid arthritis: a randomized trial. Ann Intern Med. 2007;146(6):406-15.
12. van der Bijl AE, Goekoop-Ruiterman YP, de Vries-Bouwstra JK, Ten Wolde S, Han KH, van Krugten MV, et al. Infliximab and methotrexate as induction therapy in patients with early rheumatoid arthritis. Arthritis Rheum. 2007;56(7):2129-34.

13. Moreland LW, Schiff MH, Baumgartner SW, Tindall EA, Fleischmann RM, Bulpitt KJ, et al. Etanercept therapy in rheumatoid arthritis. A randomized, controlled trial. Ann Intern Med. 1999;130(6):478-86.

14. Weinblatt ME, Kremer JM, Bankhurst AD, Bulpitt KJ, Fleischmann RM, Fox RI, et al. A trial of etanercept, a recombinant tumor necrosis factor receptor: Fc fusion protein, in patients with rheumatoid arthritis receiving methotrexate. $\mathrm{N}$ Engl $\mathrm{J}$ Med. 1999;340(4):253-9.

15. Genovese MC, Bathon JM, Martin RW, Fleischmann RM, Tesser JR, Schiff MH, et al. Etanercept versus methotrexate in patients with early rheumatoid arthritis: two-year radiographic and clinical outcomes. Arthritis Rheum. 2002;46(6):1443-50.

16. Klareskog L, van der Heijde D, de Jager JP, Gough A, Kalden J, Malaise M, et al. Therapeutic effect of the combination of etanercept and methotrexate compared with each treatment alone in patients with rheumatoid arthritis: double-blind randomised controlled trial. Lancet. 2004;363(9410):675-81.

17. Koike T, Harigai M, Inokuma S, Inoue $\mathrm{K}$, Ishiguro $\mathrm{N}$, Ryu J, et al. Postmarketing surveillance of the safety and effectiveness of etanercept in Japan. J Rheumatol. 2009;36(5):898-906.

18. Miyasaka N, Takeuchi T, Eguchi K. Guidelines for the proper use of etanercept in Japan. Mod Rheumatol. 2006;16(2):63-7.

19. Steinbrocker O, Traeger C, Batterman R. Therapeutic criteria for rheumatoid arthritis. JAMA. 1949;140:659-62.

20. Medical Dictionary for Regulatory Activities (MedDRA) Version 7.0. http://www.meddramsso.com/ (2007). Accessed 29 March 2010.

21. ICH Tripartite Harmonised Guideline. Clinical safety data management: definitions and standards for expedited reporting. http://www.pmda.go.jp/ich/e/e2a_95_3_20e.pdf (1994). Accessed 3 December 2009.

22. van Gestel AM, Prevoo ML, van 't Hof MA, van Rijswijk MH, van de Putte LB, van Riel PL. Development and validation of the European League Against Rheumatism response criteria for rheumatoid arthritis. Comparison with the preliminary American College of Rheumatology and the World Health Organization/ International League Against Rheumatism Criteria. Arthritis Rheum. 1996;39(1):34-40.

23. Feltelius N, Fored CM, Blomqvist P, Bertilsson L, Geborek P, Jacobsson LT, et al. Results from a nationwide postmarketing cohort study of patients in Sweden treated with etanercept. Ann Rheum Dis. 2005;64(2):246-52.

24. Schiff MH, Burmester GR, Kent JD, Pangan AL, Kupper H, Fitzpatrick SB, et al. Safety analyses of adalimumab (HUMIRA) in global clinical trials and US postmarketing surveillance of patients with rheumatoid arthritis. Ann Rheum Dis. 2006;65(7):889-94.

25. Takeuchi $\mathrm{T}$, Tatsuki $\mathrm{Y}$, Nogami $\mathrm{Y}$, Ishiguro N, Tanaka $\mathrm{Y}$, Yamanaka $\mathrm{H}$, et al. Postmarketing surveillance of the safety profile of infliximab in 5000 Japanese patients with rheumatoid arthritis. Ann Rheum Dis. 2008;67(2):189-94.

26. Weaver AL, Lautzenheiser RL, Schiff MH, Gibofsky A, Perruquet JL, Luetkemeyer J, et al. Real-world effectiveness of select biologic and DMARD monotherapy and combination therapy in the treatment of rheumatoid arthritis: results from the RADIUS observational registry. Curr Med Res Opin. 2006;22(1):185-98.

27. Gibofsky A, Palmer WR, Goldman JA, Lautzenheiser RL, Markenson JA, Weaver A, et al. Real-world utilization of DMARDs and biologics in rheumatoid arthritis: the RADIUS (Rheumatoid Arthritis Disease-Modifying Anti-Rheumatic Drug Intervention and Utilization Study) study. Curr Med Res Opin. 2006;22(1):169-83. 